\title{
LMDI decomposition analysis of total electricity consumption growth in Hunan province
}

\author{
Bizheng $\mathrm{Hu}^{1,2}$, Jing Liao ${ }^{1,2}$, Xingwen $\mathrm{Tu}^{3 *}$, and Xiao Zhou ${ }^{3}$ \\ ${ }^{1}$ Energy Internet Supply and Demand Operation Hunan Key Laboratory, 410000 Changsha, China \\ ${ }^{2}$ State Grid Hunan Electric Power Company Limited, Economic and Technical Research Institute, \\ 410000 Changsha, China \\ ${ }^{3}$ Hunan University, School of Economics and Trade, 410079 Changsha, China
}

\begin{abstract}
In the past decade, as an important driving force of economic growth, the China's electricity consumption growth rate has been decoupled from GDP growth rate. The economic reasons behind this abnormal phenomenon are worthy of further study. Based on the LMDI method, this paper built a model to decompose the total electricity consumption in Hunan province from 2010 to 2017 from the industrial and residential perspective. The results showed that: integrally, scale effect was the main driving factor of electricity consumption growth, intensity effect was the main inhibiting factor, and structure effect had no obvious influence; there are significant differences between the results of industrial and residential sectors, for the industry, the productive consumption intensity effect was the most significant factor that inhibited the growth of electricity consumption, while all the effects of residential sector were shown as promotion, and the increase of electricity consumption in the residential sector played a key role in the growth rate of electricity consumption in Hunan province.
\end{abstract}

\section{Introduction}

With the rapid development of China's economy and the continuous improvement of the degree of electrification, electricity consumption in China is also growing rapidly. The total electricity consumption in China has increased from 1,159.8 billion $\mathrm{kWh}$ in 1998 to $6,844.9$ billion $\mathrm{kWh}$ in 2018, an increase of 4.9 times. As the "barometer" of economic operation changes, the electricity consumption reflects the overall trend of economic operation to a certain extent. From long term, the change trend of China's electricity consumption and economic growth has strong consistency and correlation. However, in recent years, there has been a divergence between China's electricity consumption growth and its economic growth, and the gap between the two has been widening, and even in some years, GDP growth and electricity consumption growth completely deviate.

Hunan province, as a manufacturing province, faces the same challenges in the process of economic transformation and upgrading. In fact, in the early years, there was little difference between the growth rate of electricity consumption and value added in Hunan province and both of them were at a high level. However, since the "12th Five-Year Plan",

*Corresponding author: 13290037119@163.com 
the gap between them began to widen due to many factors such as the adjustment of industrial structure and internal transformation and upgrading of industry. From 2010, Hunan's electricity consumption growth and economic growth trend began to deviate significantly, and the gap between the two reached a maximum in 2014, and then the two intersected in 2018 as the growth of electricity consumption began to accelerate. The study of the reasons behind this phenomenon is of great significance to understand the relationship between electricity consumption and economic, to control the excessive growth of power consumption and to realize energy saving and the sustainable and healthy development of economy.

Electricity plays an important role in the production and consumption of goods and services, and the relationship between electricity consumption and economic growth is the focus of researchers. Based on the Granger causality test, Ma et al. (2007) ${ }^{[1]}$ and He et al. $(2017)^{[2]}$ found that electricity consumption affects economic growth. However, from the end of the 20th century, the trend of China's electricity consumption growth and economic growth began to deviate, many researchers adopted various methods to study this abnormal phenomenon. Zhu (1999) ${ }^{[3]}$ considered that industrial structure changes, adjustment of product structure within the industry are the main reasons. In view of the phenomenon that China's electricity consumption growth rate has fallen more sharply than GDP since 2008, Song and Ren (2009) ${ }^{[4]}$ argued that this is mainly due to the high intermediate input rate of heavy chemical industry, the industries electricity consumption intensity, and the economic structure. In addition, Xiao (2015) ${ }^{[5]}$ and Tan et al. (2017) ${ }^{[6]}$ also emphasized that the decrease in electricity consumption and the "destocking" of high-energy consuming products were also important reasons for the short-term deviation. However, most of above research remain at the qualitative analysis level, and fail to study the relationship between electricity consumption and economic growth from the empirical analysis level. Therefore, some researchers began to use decomposition method to study the changes in electricity consumption. Ma and Shen (2007) ${ }^{[7]}$ studied the changes in China's electricity consumption between 1984 and 2004, and the result showed that the effect of economic growth and intensity change were the main driving force. Sun and $\mathrm{Xu}(2011)^{[8]}$ found that the expansion of economic scale was the main driving force of the growth of electricity consumption in the industry. Zhang et al. (2019) ${ }^{[9]}$ found that the effect of economic activity is the main driving force of the growth of china's electricity consumption, while the energy intensity effect is the hindering factor for the growth of electricity consumption.

In short, the above studies have analyzed the electricity consumption from multiple aspects, but most of them were limited to the national level, and lack of provincial-level research. Moreover, they only focused on the industrial electricity consumption while ignored the residential electricity consumption. Based on this, this paper decomposes the growth of electricity consumption in Hunan province from 2010 and 2017, in order to analyze the reasons for the deviation of electricity consumption growth and economic growth from the provincial level. It's of great practical significance to understand the characteristics of electricity consumption in Hunan province and to formulate policies to save energy and reduce consumption, which also has a certain reference value for other provinces.

\section{LMDI decomposition model}

Logarithmic Mean Divisia Index (LMDI) is a widely used decomposition method that can identify the various driving factors that influence changes in energy consumption. Based on the original industry decomposition model, this paper adds the residential electricity consumption in an innovative way, thus further constructing a more detailed model of the total electricity consumption decomposition. Specifically, the total electricity consumption is divided into the electricity used in the industry consumption and resident consumption, and then the total electricity consumption can be expressed as following: 


$$
\begin{gathered}
E=\sum_{i} E_{p i}+E_{l} \\
\sum_{i} E_{p i}=\sum_{i} G \cdot\left(G_{i} / G\right) \cdot\left(E_{p i} / G_{i}\right)=\sum_{i} G \cdot S_{i} \cdot I_{i} \\
E_{l}=P \cdot(C / P) \cdot\left(E_{l} / C\right)=P \cdot F \cdot Q
\end{gathered}
$$

Where $E_{p i}$ is electricity consumption for the industry $i, E_{l}$ is residential electricity consumption, $G_{i}$ represents the value added of the industry $i$, and $G$ is the total value added. $S_{i}$ represents the proportion of the value added of industry $i$ in the total value added, $I_{i}$ represents the unit value added consumption of electricity, referred to as the electric intensity index. In addition, $P$ is the resident population, $C$ is the total consumption of residents, $F$ is the per capita consumption, $Q$ is the residential electricity consumption intensity.

Considering that electricity consumption is a aggregate indicator, the addition form method is more suitable. Therefore, the addition form of LMDI can decompose the change of total electricity consumption in a period of time into the following formula:

$$
\begin{aligned}
& \Delta E_{p}=E_{p}^{t}-E_{p}^{0}=\Delta E_{a c t}+\Delta E_{s t r}+\Delta E_{p r o_{-} i n t} \\
& \Delta E_{l}=E_{l}^{t}-E_{l}^{0}=\Delta E_{p o p}+\Delta E_{c o n}+\Delta E_{\text {con_int }}
\end{aligned}
$$

Where the specific effect values of each driving factor were as follows: economic scale effect: $\Delta E_{a c t}=\sum_{i} L_{1} \cdot \ln \left(G^{t} / G^{o}\right)$; industrial structure effect: $\Delta E_{s t r}=\sum_{i} L_{1} \cdot \ln \left(S_{i}^{t} / S_{i}^{0}\right)$; productive consumption intensity effect: $\Delta E_{\text {pro_int }}=\sum_{i} L_{1} \cdot \ln \left(I_{i}^{t} / I_{i}^{0}\right)$; population scale effect: $\Delta E_{\text {pop }}=L_{2} \cdot \ln \left(P^{t} / P^{o}\right) ;$ residential consumption level effect: $\Delta E_{\text {con }}=L_{2} \cdot \ln \left(F^{t} / F^{o}\right)$; residential consumption intensity effect: $\Delta E_{\text {con_int }}=L_{2} \cdot \ln \left(Q^{t} / Q^{o}\right)$. Among them, $L_{2}=\left(E_{p i}^{t}-E_{p i}^{0}\right) /\left(\ln E_{p i}^{t}-\ln E_{p i}^{0}\right) \quad$ and $\quad L_{2}=\left(E_{l}^{t}-E_{l}^{0}\right) /\left(\ln E_{l}^{t}-\ln E_{l}^{0}\right) \quad$ are log-average equations. The economic scale effect refers to changes in electricity consumption caused only by economic scale changes, and other effects are similar.

\section{Decomposition results and analysis}

\subsection{Decomposition results of the industrial electricity consumption}

Since the growth rate of value added and electricity consumption have changed a lot in 2014, we use 2014 as a boundary in order to explore the causes of the differences before and after this important node. As can be found from Fig. 1(a), the total effect was at a high level in 2010-2014 indicating that electricity consumption growth mainly occurs in the first half of the period, which is consistent with the trend of electricity consumption growth in section 1 . According to the decomposition results, the economic scale effect is the main driving force behind the fluctuation, which has increased the industrial electricity consumption by more than 20 billion $\mathrm{kWh}$ in both time periods. The industrial structure effect is positive in 20102014 and negative in 2014-2017, which means that the industrial electricity consumption has decreased due to the restructuring of the industry in Hunan province in recent years. In 
addition, the productive consumption intensity effect has been a major factor in the growth of electricity consumption throughout the study period, reducing industrial electricity consumption by 29.92 and 20.97 billion kWh respectively, in 2010-2014 and 2014-2017.

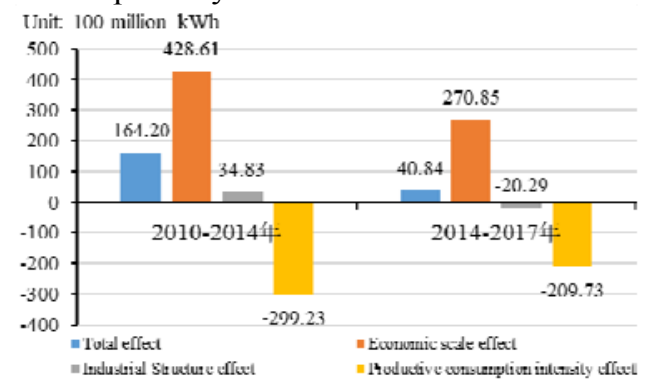

(a) by period

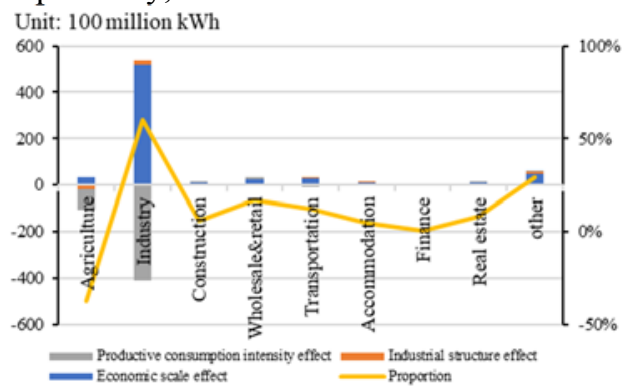

(b) industry

Data source: author calculated according to the data provided by State Grid Hunan Electric Power Company Limited and Hunan Provincial Bureau of Statistics.

Fig. 1. Decomposition results of industrial electricity consumption in 2010-2017.

As shown in Fig. 1(b), industry accounted for the largest share of the total effect, reaching $60 \%$, which means that $60 \%$ of the increase in electricity consumption in Hunan province in 2010-2017 was contributed by the increase in industrial electricity consumption. Agriculture, forestry, animal husbandry and fishery is the only industry which lead to less electricity consumption, this abnormal decline is most likely due to the "12th Five-Year Plan" period of the industrial electricity consumption caliber adjustment is larger. In terms of each industry's effects, the three types of effects are dispersed to different industries with different performance. The economic scale effect, which is positive and accounts for the largest proportion in all industries, is the main driver of the increase in electricity consumption in all industries, the industrial structure effect slightly promotes electricity consumption in industries other than agriculture, forestry, animal husbandry and fisheries, and the intensity effect of production and consumption is acting as a driving force in industries such as construction, wholesale and retail trade, while the effect is inhibited in agriculture, etc.

\subsection{Decomposition results of the total electricity consumption}

As can be found from Table 1, the performance of the total effect and the different effects that distinguish industries and residents varies over time, characterized by the following:

(1) Overall, electricity consumption increased by 409.80 million $\mathrm{kWh}$ in 2017 compared to 2010, a large part of which occurred between 2010 and 2014. The total industry effect is similar, contributing significantly more in 2010-2014 than in 2014-2017. While the total resident effect is the opposite, with more increases in 2014-2017.

(2) Distinguishing between industrial and residential electricity consumption, the contribution of the two during the period is basically equal, but it is very different in terms of time period. Specifically, in 2010-2014, the electricity consumption growth mainly depended on the driving force provided by the industrial electricity consumption, while in 2014-2017 it was mainly driven by residential electricity.

(3) In terms of the industrial sub-effect, whether in the full-time or time-period, the economic scale effect significantly promotes the increase of electricity consumption, while the productive consumption intensity effect is shown as a significant inhibition effect. It is worth noting that in 2010-2014, the industrial structure effect promoted electricity consumption growth, while this effect changed from positive to negative in 2014-2017. The reason for transformation is that the industry structure of Hunan province has been adjusted 
during this period, that is, the high-power-consuming industry has been transformed into a low-power-consuming industry due to energy conservation and emission reduction policies.

(4) In contrast, the residential sub-effect is more stable. Whether in the full-time or timeperiod, the population scale effect, the residential consumption level and residential consumption intensity effect all promote the increase of the residential electricity consumption. In addition, the residential consumption intensity effect has always been the main contributor to the residential electricity consumption growth, the residential consumption level effect is second, and the population scale effect is the least effective.

Table 1. Decomposition results of the total electricity consumption (Unit: billions kWh).

\begin{tabular}{|c|c|c|c|c|c|c|c|c|c|}
\hline \multirow{2}{*}{\begin{tabular}{c} 
period Effect \\
\cline { 3 - 10 }
\end{tabular}} & \multirow{2}{*}{$\begin{array}{c}\text { Total } \\
\text { effect }\end{array}$} & Total & $\begin{array}{c}\text { Economic } \\
\text { scale } \\
\text { effect }\end{array}$ & $\begin{array}{c}\text { Industrial } \\
\text { structure } \\
\text { effect }\end{array}$ & $\begin{array}{c}\text { Productive } \\
\text { consumption } \\
\text { intensity } \\
\text { effect }\end{array}$ & Total & $\begin{array}{c}\text { Population } \\
\text { scale } \\
\text { effect }\end{array}$ & $\begin{array}{c}\text { Residential } \\
\text { consumption } \\
\text { level effect }\end{array}$ & $\begin{array}{c}\text { Residential } \\
\text { consumption } \\
\text { intensity } \\
\text { effect }\end{array}$ \\
\hline $2010-2017$ & 409.80 & 205.04 & 699.46 & 14.54 & -508.96 & 204.76 & 12.60 & 59.08 & 133.08 \\
\hline $2010-2014$ & 259.16 & 164.20 & 428.61 & 34.83 & -299.23 & 94.96 & 6.25 & 32.82 & 55.89 \\
\hline $2014-2017$ & 150.64 & 40.84 & 270.85 & -20.29 & -209.73 & 109.80 & 6.35 & 26.26 & 77.19 \\
\hline
\end{tabular}

\section{Conclusion and suggestion}

This paper used LMDI method to make an exponential decomposition of the growth of electricity sales in Hunan province from 2010 to 2017 from multiple perspectives, so as to understand the motivation behind the change of electricity consumption in a more detailed and comprehensive way. The results showed that the rapid expansion of economic scale was the primary factor and main driving force for the growth of electricity consumption by the industry and the total, and the residential consumption intensity effect was the main driving factor for the growth of residential electricity consumption. The productive consumption intensity effect was the main restraining factor for the growth of electricity consumption in industry and the total. In the 2010-2014 period, industry electricity consumption was the main driving force for the increase in total electricity consumption, while in the 2014-2017 period, the increase was mainly driven by residential electricity consumption.

According to the conclusions and combined with the actual situation of Hunan province, this paper put forward several specific suggestions as follows. First, promote the marketoriented reform of electric power and the structural reform of the power supply side. Second, encourage and guide transformation of industrial structure to the structure of low energy consumption. Finally, improve the consumption level of residents to strengthen the two-way promotion between residents' welfare and social electricity consumption.

\section{References}

1. X. Ma, Y. X. Zhu, X. B. Li, Statistics \& Decision, 5, 100 (2007).

2. Y. M. He, T. M. J. Fullerton, A. G. Walke, Energy Economics, 63, 154 (2017).

3. H. Zhu, China Statistics, 4, 24 (1999).

4. R. L. Song, Z. P. Ren, Statistical Research, 8, 34 (2009).

5. H. W. Xiao, Macroeconomic Management, 6, 27 (2015).

6. X. D. Tan, B. G. Shan, S. S. Wu, B. P. Shan, Electric power, 50, 5 (2017).

7. J. X. Ma, S. J. Shen, Statistics \& decision, 12, 79 (2007).

8. N. Sun, J. Y. Xu, Resources and Environment in The Yangtze Basin, 20, 918 (2011).

9. C. Zhang, B. Su, K. Zhou, S. Yang, Journal of Cleaner Production, 209, 224 (2019). 